\title{
Cloud-Aerosol Interactions: Retrieving Aerosol Ångström EXPONENTS FROM CALIPSO MEASUREMENTS OF OPAQUE WATER ClOUdS
}

\author{
Mark Vaughan ${ }^{1 *}$, Zhaoyan Liu ${ }^{1,2}$, Yong-Xiang Hu${ }^{1}$, Kathleen Powell ${ }^{1}$, Ali Omar ${ }^{1}$, Sharon Rodier ${ }^{1,2}$, \\ William Hunt $^{1,2}$, Jayanta Kar ${ }^{1,2}$, Jason Tackett ${ }^{1,2}$, Brian Getzewich ${ }^{1,2}$, Kam-Pui Lee ${ }^{1,2}$ \\ ${ }^{1}$ NASA Langley Research Center, Hampton,VA 23681, USA, *Email: mark.a.vaughan@nasa.gov \\ ${ }^{2}$ Science Systems and Applications, Inc. (SSAI), Hampton, VA 23666, USA
}

\begin{abstract}
Backscatter and extinction from water clouds are well-understood, both theoretically and experimentally, and thus changes to the expected measurement of layer-integrated attenuated backscatter can be used to infer the optical properties of overlying layers. In this paper we offer a first look at a new retrieval technique that uses CALIPSO measurements of opaque water clouds to derive optical depths and Ångström exponents for overlying aerosol layers.
\end{abstract}

\section{INTRODUCTION}

$\mathrm{Hu}$ et al., 2007 [1] introduced a technique to retrieve optical depths for aerosol layers lying above opaque water clouds (OWC). For a nadirviewing, polarization-sensitive lidar operating at wavelength $\lambda$, the layer integrated attenuated backscatter for water clouds, $\gamma^{\prime}{ }_{w}, \lambda$, is given by [1]

$$
\begin{aligned}
\gamma_{w, \lambda}^{\prime} & =\exp \left(-2 \int_{0}^{z_{\text {top }}} \sigma_{a, \lambda}(r) d r\right) \int_{z_{\text {top }}}^{z_{\text {tase }}} \mathrm{B}_{\lambda}(r) d r \\
& =\mathrm{T}_{\mathrm{a}, \lambda}^{2}\left(0, \mathrm{z}_{\text {top }}\right) \frac{1-\mathrm{T}_{w, \lambda}^{2}\left(\mathrm{z}_{\text {top }}, \mathrm{z}_{\text {base }}\right)}{2 \eta_{w, \lambda} \mathrm{S}_{w, \lambda}} .
\end{aligned}
$$

In this expression, $B_{\lambda}(r)$ is the measured attenuated total backscatter coefficient at range $r$ with corrections applied for molecular and ozone attenuation. $\mathrm{T}_{\mathrm{a}, \lambda}^{2}\left(0, \mathrm{z}_{\mathrm{top}}\right)$ is the aerosol two-way transmittance between the lidar and cloud top. Similarly $\mathrm{T}^{2}{ }_{w}, \lambda\left(\mathrm{z}_{\mathrm{top}}, \mathrm{z}_{\mathrm{base}}\right)$ is the two-way transmittance of the water cloud between $z_{\text {top }}$ and $z_{\text {base }} . \quad S_{w, \lambda}$ is the water cloud lidar ratio, which can either be established empirically or derived theoretically from Mie calculations, and $\eta_{w}$ is the water cloud layereffective multiple scattering factor, which can be obtained from the cloud layer-integrated volume depolarization ratio, $\delta_{w}, \lambda$. For OWCs, $\mathrm{T}^{2}{ }_{w}, \lambda\left(\mathrm{z}_{\mathrm{top}}\right.$, $\left.\mathrm{z}_{\text {base }}\right)=0$, and thus the aerosol optical depth
(AOD) for aerosol layers lying above OWCs can be retrieved using [1]

$$
\begin{aligned}
\tau_{\mathrm{a}, \lambda} & =-\frac{1}{2} \ln \left(2 \mathrm{~S}_{w, \lambda} \gamma_{w, \lambda}^{\prime} \eta_{w, \lambda}\right) \\
& =-\frac{1}{2} \ln \left(2 \mathrm{~S}_{w, \lambda} \gamma_{w, \lambda}^{\prime}\left(\frac{1-\delta_{w, \lambda}}{1+\delta_{w, \lambda}}\right)^{2}\right)
\end{aligned}
$$

Since its introduction, the OWC retrieval technique has been used extensively with CALIPSO data to, among other things, investigate "direct climate forcing by absorbing aerosols located above boundary layer clouds" [2] and to characterize lidar ratios of dust and smoke transported from Africa out over the Atlantic Ocean [3]. However, while the CALIPSO lidar makes backscatter measurements at both $532 \mathrm{~nm}$ and $1064 \mathrm{~nm}$, depolarization is only measured in the $532 \mathrm{~nm}$ channel [4], and thus the $\mathrm{Hu}$ OWC technique cannot be applied to CALIPSO 1064 nm data.

\section{1064 nm OWC RETRIEVAL TECHNIQUE}

Figure 1 shows CALIPSO measurements acquired off the southwest coast of Africa on 12 July 2008. On the left side of the images a smoke plume is seen lying over a largely opaque stratus deck. The smoke layer is not present on the right side. The presence/absence of the smoke layer is clearly reflected in the magnitude of the OWC attenuated backscatter color ratio $(1064 \mathrm{~nm} / 532 \mathrm{~nm})$ shown in the lower panel. In the clear air regions south of $\sim 22^{\circ} \mathrm{S}$, the OWC color ratios lie between 1.1 and 1.2 , whereas beneath the smoke layer (e.g., at $\sim 9.7^{\circ} \mathrm{S}$ ) the OWC color ratios can exceed 1.6. The higher OWC color ratios occur because smoke attenuates the $532 \mathrm{~nm}$ signal much more rapidly than it does the $1064 \mathrm{~nm}$ signal. We can quantify the attenuation differences using layerintegrated attenuated color ratio, $\chi^{\prime}$; i.e., 


$$
\chi^{\prime}=\frac{\gamma_{w, 1064}^{\prime}}{\gamma_{w, 532}^{\prime}}=\frac{\mathrm{T}_{\mathrm{a}, 1064}^{2}\left(0, \mathrm{z}_{\text {top }}\right) \int_{\mathrm{z}_{\text {top }}}^{\mathrm{z}_{\text {tase }}} \mathrm{B}_{1064}(\mathrm{z}) \mathrm{dz}}{\mathrm{T}_{\mathrm{a}, 532}^{2}\left(0, \mathrm{z}_{\text {top }}\right) \int_{\mathrm{z}_{\text {top }}}^{\mathrm{b}_{\text {base }}} \mathrm{B}_{532}(\mathrm{z}) \mathrm{dz}}
$$

In clear skies having negligible particulate loading above an OWC (e.g., as in the right side of Figure $1), \mathrm{T}_{\mathrm{p}, 532}^{2}\left(0, \mathrm{z}_{\mathrm{top}}\right)=\mathrm{T}_{\mathrm{p}, 1064}^{2}\left(0, \mathrm{z}_{\mathrm{top}}\right)=1$ and thus

$$
\chi_{\text {clear }}^{\prime}=\int_{z_{\text {top }}}^{z_{\text {tose }}} B_{1064}(z) d z / \int_{z_{\text {top }}}^{z_{\text {base }}} B_{532}(z) d z
$$

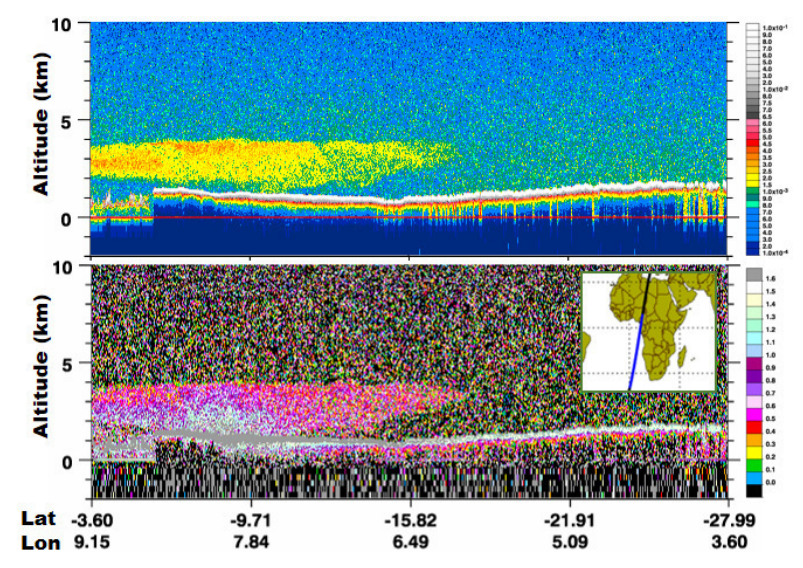

Figure 1: Version 4.00 CALIPSO nighttime data acquired 12 July 2008; upper panel shows $532 \mathrm{~nm}$ attenuated backscatter coefficients while the lower panel shows the attenuated backscatter color ratios (i.e., the $1064 \mathrm{~nm}$ attenuated backscatter coefficients divided by the $532 \mathrm{~nm}$ attenuated backscatter coefficients).

When aerosol layers lie above, $\chi_{\text {clear }}^{\prime}$ is rescaled by the ratio of the aerosol two-way transmittances; that is

$$
\chi^{\prime}=\left(\frac{\mathrm{T}_{\mathrm{a}, 1064}^{2}\left(0, \mathrm{z}_{\text {top }}\right)}{\mathrm{T}_{\mathrm{a}, 532}^{2}\left(0, \mathrm{z}_{\text {top }}\right)}\right) \chi_{\text {clear }}^{\prime} .
$$

Using equation (5) we can derive estimates of the AOD at $1064 \mathrm{~nm}$ :

$$
\tau_{1064}=-0.5 \ln \left(\mathrm{T}_{\mathrm{a}, 532}^{2}\left(0, \mathrm{z}_{\text {top }}\right) \frac{\chi^{\prime}}{\chi_{\text {clear }}^{\prime}}\right) \text {. }
$$

Note that the parameters on the right hand side of equation (6) are all potentially known values. $\chi^{\prime}$ is a direct measurement; $\tau_{\mathrm{a}, 532}$ and hence $\mathrm{T}_{\mathrm{a}, \mathrm{\lambda}}^{2}\left(0, \mathrm{z}_{\mathrm{top}}\right)$ can be retrieved using the $\mathrm{Hu}$ OWC technique; and, as described in the following section, high quality estimates of $\chi_{\text {clear }}^{\prime}$ can be obtained empirically from the 9-year CALIPSO data set.

\section{CHARACTERIZING $\chi_{\text {clear }}^{\prime}$ FOR OWC}

Obtaining reliable measurements of $\chi_{\text {clear }}^{\prime}$ depends on several factors: cloud top and base must be accurately detected and $\gamma^{\prime}{ }_{w}, 532$ must be corrected for contributions from molecular scattering (e.g., as described in [5]); even faint aerosol loading of the atmosphere above OWC must be confidently identified and rigorously excluded; and, most importantly, the signals in all channels must be accurately calibrated. To best satisfy the final requirement, in this study we use the CALIPSO version 4.00 level 1 nighttime data, which delivers improved calibrations, especially at $1064 \mathrm{~nm}$ [6]. To achieve the requirements imposed by the penultimate condition, we used the CALIPSO simulator [7] to generate "known to be clear" test data, from which we established the mean and standard deviation of the $532 \mathrm{~nm}$ integrated attenuated backscatter within a purely molecular atmosphere as a function of altitude. To be included in the data set from which $\chi_{\text {clear }}^{\prime}$ was calculated

(a) a candidate cloud must have a top below $3 \mathrm{~km}$ and be the only layer detected in a 5-km horizontal average;

(b) all candidate clouds must be classified as opaque, and have minimum values of $\gamma_{w^{\prime}}, \geq 0.04$ $\mathrm{sr}^{-1}$ at both $532 \mathrm{~nm}$ and $1064 \mathrm{~nm}$;

(c) cloud top temperature must be greater than $0^{\circ} \mathrm{C}$; and

(d) the integrated attenuated backscatter of the "clear air" above cloud top must lie within \pm 1 standard deviation of the corresponding mean value obtained from Figure 2.

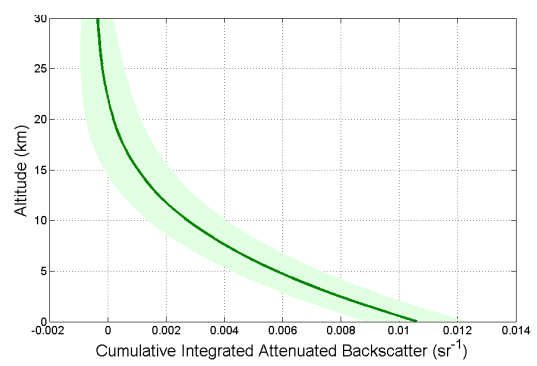

Figure 2: cumulative integrated attenuated backscatter at $532 \mathrm{~nm}$ as a function of altitude. The dark green line represents the mean calculated over 3404 simulated profiles. A one standard deviation uncertainty envelope is shown in pale green. 
The resulting distribution of $\chi_{\text {clear }}^{\prime}$ values obtained from the V4 CALIPSO data acquired globally during all of 2008 is shown in Figure 3. The distribution is both tight and symmetric: the median is essentially identical to the mean, and the standard deviation is $\sim 4 \%$ of the mean.

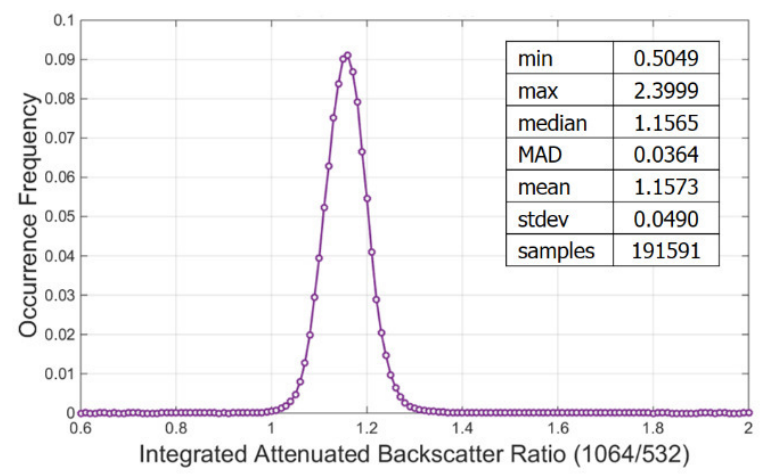

Figure 3: distribution of $X^{\prime}$ clear for opaque water clouds measured by CALIPSO during all of 2008 .

Absent multiple scattering effects, $\chi_{\text {clear }}^{\prime}$ is simply the ratio of water cloud lidar ratios at the two wavelengths; i.e., $\boldsymbol{\chi}_{\text {clear }}^{\prime}=\mathrm{S}_{w, 532} / \mathrm{S}_{w}, 1064$. However, multiple scattering can never be neglected in the analysis of CALIPSO water cloud measurements, and thus in practice

$$
\chi_{\text {clear }}^{\prime}=\frac{\eta_{w, 532} S_{w, 532}}{\eta_{w, 1064} S_{w, 1064}}=\left(\frac{\eta_{w, 532}}{\eta_{w, 1064}}\right)\left(\frac{S_{w, 532}}{S_{w, 1064}}\right) \text {. }
$$

\section{AEROSOL ÅNGSTRÖM EXPONENTS}

As a first test, we applied our retrieval scheme to nighttime data acquired during June-September 2008 over the same smoke transport region off the southwest coast of Africa $\left(0^{\circ}-20^{\circ} \mathrm{S}, 5^{\circ} \mathrm{W}-15^{\circ} \mathrm{E}\right)$ that was analyzed in [3]. Aerosol above cloud (AOC) samples were identified by applying criteria (a) and (b) used to establish $\chi_{\text {clear. }}^{\prime}$. However, for the AOC data set no restrictions were placed on the cloud integrated attenuated backscatters. Furthermore, to assure the presence of a reasonable amount of aerosol loading, the 532 $\mathrm{nm}$ integrated attenuated backscatter above cloud top was required to exceed the mean plus four standard deviations of the corresponding mean value obtained from Figure 2.

Choosing a region largely dominated by smoke allows us to make an initial assessment of the effectiveness of the method by comparing the retrieved aerosol extinction Ångström exponents to an expected value of $\sim 2$ (e.g., see [2] and references therein). We compute the Ångström exponents, $\alpha$, using the $532 \mathrm{~nm}$ AOD derived from the $\mathrm{Hu}$ OWC technique (i.e., equation (2)) and the $1064 \mathrm{~nm}$ AOD from equation (6):

$$
\alpha=-\log \left(\tau_{1064} / \tau_{532}\right) / \log (1064 / 532) \text {. }
$$

The Ångström exponent distribution obtained from the AOC data set is shown in Figure 4. From a proof of concept point of view, the most important characteristics of this distribution are that the mode and mean values are both $\sim 2$, which is wonderfully consistent with our initial expectations. On the other hand, the distribution is substantially broader than the distribution of $\chi_{\text {clear }}^{\prime}$, with a standard deviation approximately equal to $\sim 60 \%$ of the mean. However, this should not be too surprising, given that the signal-to-noise ratios (SNR) within opaque water clouds (i.e., where $\chi_{\text {clear }}^{\prime}$ is measured) can be two orders of magnitude larger than the typical SNR for CALIPSO aerosol measurements. Furthermore, the fact that the median absolute distance (MAD) is much smaller (at $\sim 26 \%$ of the median) suggests that the relatively large standard deviation is influenced more by large outliers than by an overall dispersion of the values.

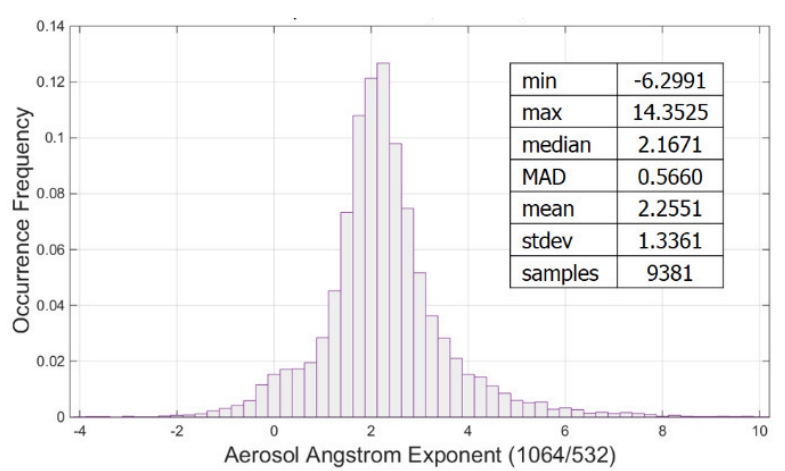

Figure 4: distribution of aerosol Angstrom exponents for June-September 2008

\section{NEXT STEPS}

Clearly the next step in the development of this technique will be to use the $1064 \mathrm{~nm}$ AODs obtained from equation (6) as constraints to retrieve estimates of $1064 \mathrm{~nm}$ lidar ratios (e.g., as is done at $532 \mathrm{~nm}$ in [3]). However, whether this can be done reliably with the standard CALIPSO data products remains to be seen, as the above- 
cloud $1064 \mathrm{~nm}$ signals will likely require considerably more spatial averaging than the 532 nm signals.

In closing, we note that this work used a research version of the CALIPSO level 2 products created by applying the CALIPSO V3.30 level 2 analysis software to the newly released V4.00 level 1 data. However, while a full suite of level 2 products was generated, this investigation did not use the CALIPSO aerosol data products. Instead, the results presented here were derived from information reported in the CALIPSO level 1B products and level $25-\mathrm{km}$ cloud layer products: aerosol optical depths and Ångström exponents are derived solely from changes to the measured optical properties of clouds that occur in the presence of above-cloud aerosols (e.g., as seen in Figure 1).

\section{REFERENCES}

[1] Hu, Y., M. Vaughan, Z. Liu, K. Powell, and S. Rodier, 2007: Retrieving Optical Depths and Lidar Ratios for Transparent Layers Above Opaque Water Clouds From CALIPSO Lidar Measurements, IEEE Geosci. Remote Sens. Lett., 4, 523526, doi:10.1109/LGRS.2007.901085.

[2] Chand, D., T. L. Anderson, R. Wood, R. J. Charlson, Y. Hu, Z. Liu, and M. Vaughan, 2008: Quantifying above-cloud aerosol using spaceborne lidar for improved understanding of cloudy-sky direct climate forcing, J. Geophys. Res., 113, D13206, doi:10.1029/ 007JD009433.
[3] Liu, Z., D. Winker, A. Omar, M. Vaughan, J. Kar, C. Trepte, Y. Hu and G. Schuster, 2015: Evaluation of CALIOP 532-nm AOD over Opaque Water Clouds, Atmos. Chem. Phys., 15, 1265-1288, doi:10.5194/acp-15-1265-2015.

[4] Hunt, W. H., D. M. Winker, M. A. Vaughan, K. A. Powell, P. L. Lucker, and C. Weimer, 2009: "CALIPSO Lidar Description and Performance Assessment", J. Atmos. Oceanic Technol., 26, 1214-1228, doi:10.1175/2009JTECHA1223.1.

[5] Vaughan, M. A., Z. Liu, M. J. McGill, Y. Hu, and M. D. Obland, 2010: On the Spectral Dependence of Backscatter from Cirrus Clouds: Assessing CALIOP's $1064 \mathrm{~nm}$ Calibration Assumptions Using Cloud Physics Lidar Measurements", J. Geophys. Res., 115, D14206, doi:10.1029/2009JD013086.

[6] Vaughan, M., A. Garnier, Z. Liu, D. Josset, Y. Hu, K.-P. Lee, W. Hunt, J.-P. Vernier, S. Rodier, J. Pelon, and D. Winker, 2012: Chaos, Consternation and CALIPSO Calibration: New Strategies for Calibrating the CALIOP $1064 \mathrm{~nm}$ Channel, 26th International Laser Radar Conference (ILRC), Porto Heli, Greece.

[7] Powell, K. A., Liu, Z., and W. H. Hunt, 2006: Simulation of Random Electron Multiplication in CALIPSO Lidar Photomultipliers, 23rd International Laser Radar Conference (ILRC), Nara, Japan. 